\title{
Alterations in microbiota and fermentation products in equine large intestine in response to dietary variation and intestinal disease
}

\author{
Kristian Daly ${ }^{1}$, Christopher J. Proudman ${ }^{2}$, Sylvia H. Duncan ${ }^{3}$, Harry J. Flint ${ }^{3}$, Jane Dyer ${ }^{1}$ and \\ Soraya P. Shirazi-Beechey ${ }^{1 *}$ \\ ${ }^{1}$ Epithelial Function and Development Group, Department of Cellular and Molecular Physiology, Faculty of Health and \\ Life Sciences, University of Liverpool, Brownlow Hill, Liverpool L69 7ZJ, UK \\ ${ }^{2}$ Equine Division, Department of Veterinary Clinical Sciences, University of Liverpool, Leahurst, Neston CH64 7TE, UK \\ ${ }^{3}$ Microbial Ecology Group, The Rowett Institute of Nutrition and Health, University of Aberdeen, Greenburn Road, \\ Bucksburn, Aberdeen AB21 9SB, UK
}

(Submitted 19 January 2011 - Final revision received 16 June 2011 - Accepted 16 June 2011 - First published online 5 August 2011)

\section{Abstract}

We aimed to determine the effects of variations in dietary composition on equine gut microbiota and their fermentation products, and proposed that dietary modifications profoundly affect microbial ecosystems and their metabolites. Bacterial communities within the large intestine of three groups of horses were compared using oligonucleotide-RNA hybridisation methodology. Each group consisting of six horses was maintained on (1) a grass-only diet, (2) a concentrate diet (i.e. supplemented with hydrolysable carbohydrates) and (3) a concentrate diet but horses were affected by simple colonic obstruction and distension (SCOD), a prevalent form of dietary-induced intestinal disease. We show that in response to dietary change and intestinal disease, there is a progressive and significant increase in Lachnospiraceae, the Bacteroidetes assemblage and the lactic acid-producing, Bacillus-Lactobacillus-Streptococcus (BLS) group. In contrast, there is a corresponding decrease in the proportion of obligate fibrolytic, acid-intolerant bacteria, Fibrobacter and Ruminococcaceae. Assessment of monocarboxylic acids indicated that there are significantly higher concentrations of lactic acid in the colonic contents of horses maintained on a concentrate diet and those suffering from SCOD, correlating with the observed increase in the population abundance of the BLS group. However, the population size of the Veillonellaceae (lactate utilisers) remained constant in each study group. The inability of this group to respond to increased lactic acid may be a contributory factor to the build-up of lactic acid observed in horses fed a concentrate diet and those suffering from SCOD.

Key words: Equine intestine: Intestinal microbiota: Diet

Horses are trickle feeders possessing a voluminous and elaborate large intestinal tract. They are hindgut fermenters with a complex microbial digestion uniquely adapted to grazing on high-fibre, low-energy fodder. Domestication of the horse has led to this natural pattern of feeding and digestion being disrupted. Consequently, gastrointestinal dysfunction, such as colic, is the single most important cause of mortality among domesticated horses ${ }^{(1-7)}$.

The microbial hydrolysis of dietary plant fibre (grass) within the large intestine leads to the release of soluble sugars, which are subsequently fermented to monocarboxylates, notably acetate, propionate and butyrate, referred to as SCFA. A large proportion (60-70\%) of the horse's body energy is provided by SCFA absorbed from the caecum and the colon ${ }^{(8-10)}$. However, to provide further energy for the demands of work and athletic performance, many horses are fed diets containing readily hydrolysable carbohydrates ( $\mathrm{hCHO}$ ), generally in the form of grain (starch); commonly referred to as concentrate diets. There is strong epidemiological evidence for the feeding of hCHO as a risk factor for equine intestinal dysfunction $^{(7)}$. This includes evidence of a dose-response relationship between the amount of $\mathrm{hCHO}$ and the risk of disease $^{(3,6,11)}$. It is suggested that when horses are introduced to diets containing high levels of hCHO $(>0.4 \%$ of body weight), a substantial proportion of starch escapes hydrolysis in the small intestine. This reaches the large intestine ${ }^{(12-14)}$, where it is fermented to products such as lactic acid and $\mathrm{CO}_{2}$. It has been demonstrated that there is a significant increase in lactic acid concentration in the colon of horses fed high-grain diets ${ }^{(15)}$. This is accompanied by a significant

Abbreviations: BLS, Bacillus-Lactobacillus-Streptococcus; CFB, Cytophaga-Flexibacter-Bacteroides; hCHO, hydrolysable carbohydrates; rRNA, ribosomal RNA; SCOD, simple colonic obstruction and distension; SSU, small subunit.

* Corresponding author: Professor S. P. Shirazi-Beechey, email spsb@liverpool.ac.uk 
decrease in caecal/colonic $\mathrm{pH}$ (from $>7.5$ to $<6.2)^{(15,16)}$, leading to perturbation in the microbiota $^{(1,17)}$ disposing the horse to intestinal dysfunction. However, little information is available on the precise changes that may occur in these microbial ecosystems and their underlying mechanisms.

We previously investigated the molecular diversity of the microbiota in the large intestine of horses maintained on pasture forage by the analysis of PCR-amplified small subunit (SSU) ribosomal RNA (rRNA) gene sequences ${ }^{(18,19)}$. We showed that the majority of the recovered sequences are phylogenetically affiliated to several known groups of anaerobic bacteria, namely the low $\% \mathrm{G}+\mathrm{C}$ Gram-positive bacteria belonging to the phylum Firmicutes, especially the Lachnospiraceae (cluster XIVa of the Clostridiaceae), and the phylum Bacteroidetes, previously known as the CytophagaFlexibacter-Bacteroides (CFB) phylum. Other notable members included the Fibrobacter, the Ruminococcaceae and the Bacillus-Lactobacillus-Streptococcus (BLS) group of Firmicutes. These studies revealed that the Lachnospiraceae, the Bacteroidetes and the Spirochaetaceae make up the largest proportion of bacteria in the equine hindgut.

In the present study, we have used oligonucleotide-RNA hybridisation methodology to characterise and compare the abundance of these predominant bacterial communities. We have also measured microbial fermentation products in the colonic contents of three groups of horses, maintained on a grass-only diet or a concentrate diet or affected by simple colonic obstruction and distension (SCOD), a prevalent form of dietary-induced intestinal disease.

\section{Methods \\ Collection of equine colonic samples}

Samples of large-intestinal contents were obtained from six freshly slaughtered horses from the local abattoir (Nantwich, Cheshire, UK) (Group 1). They had been maintained on pasture forage in the mid-Cheshire area with ad libitum access to mature grass comprising mainly of Lolium perenne (average nutritional value $8.5 \mathrm{~kJ}$ of digestible energy/g DM). Groups 2 and 3 comprised twelve horses in light work and were maintained on concentrate feed rich in sugar and starch, either euthanised for reasons other than intestinal disease, mainly limb injuries (six horses) or undergoing surgery after diagnosis of SCOD (six horses) at the University of Liverpool (Liverpool, UK) Philip Leverhulme Equine Hospital. SCOD is the clinical diagnosis assigned to a number of non-ischaemic diseases of the equine colon (e.g. pelvic flexure impaction, colonic displacement and nephrosplenic entrapment) that result in severe abdominal pain. Surgical treatment is indicated for the successful resolution of some types of SCOD. The precise dietary formulations and individual additives given to horses were not available. However, the core diet for all concentrate-fed horses consisted of a coarse mix balancer (2$2.5 \mathrm{~kg} / \mathrm{d} ; 20-25 \mathrm{~kJ}$ digestible energy $/ \mathrm{g})$, hay/haylage $(6 \mathrm{~kg} / \mathrm{d}$; $60 \mathrm{~kJ}$ digestible energy $/ \mathrm{g})$ and barley $(1 \mathrm{~kg} / \mathrm{d} ; 13 \mathrm{~kJ}$ digestible energy/g). A typical coarse mix composition is micronised cereal, grass/alfalfa pellets, molasses, vegetables and herbs.
The time between the last meal and collection of samples was between 12 and $16 \mathrm{~h}$ in all cases. The animals sampled for the present study were all client-owned horses undergoing euthanasia or veterinary treatment, and hence outside the scope of the Animals (Scientific Procedures) Act 1986. The samples from client-owned animals undergoing veterinary treatment were obtained with the informed consent of their owners, in accordance with University of Liverpool policies.

The horses were adult ( $7-12$ years old) mares and geldings of various breeds. Euthanasia was either by captive bolt (abattoir) or by the injection of a barbiturate (Philip Leverhulme Equine Hospital). The anaesthetised horses received thiopentane, ketamine and isoflurane. There is no evidence that any of these drugs influence gut microbiota. The horses had not received antibiotics at the time of sampling. Gut contents from the pelvic flexure region of the large intestine were removed promptly (within $10 \mathrm{~min}$ ), after death or during surgery, placed in cryogenic tubes, frozen in liquid $\mathrm{N}_{2}$ and subsequently stored at $-80^{\circ} \mathrm{C}$ until use.

\section{Extraction of nucleic acid from gut content samples}

Nucleic acid was extracted from samples of gut contents using the method outlined by Lin \& Stahl ${ }^{(20)}$ and as described previously $^{(18,19)}$. Frozen samples were thawed, and approximately $1 \mathrm{~g}$ aliquots were transferred to $2 \mathrm{ml}$ screw-cap tubes containing $50 \mu \mathrm{l}$ of $20 \%$ (w/v) SDS, $500 \mu \mathrm{l}$ phenol equilibrated with a $0 \cdot 1 \mathrm{M}$-citrate buffer ( $\mathrm{pH} 4 \cdot 3$ ) (Sigma-Aldrich Company Limited, Poole, Dorset, UK) and sterile acid-washed glass beads $(0.1 \mathrm{~mm}$ diameter $)$. The samples were beaten for $2 \mathrm{~min}$ at room temperature using a mini beadbeater (Biospec Corporation, Bartlesville, OK, USA; Stratech Scientific, Newmarket, Suffolk, UK) and transferred to a $60^{\circ} \mathrm{C}$ water bath for $10 \mathrm{~min}$ before an additional $1 \mathrm{~min}$ of beating. The aqueous supernatant was extracted again with buffer-equilibrated phenol and then an additional three times with phenolchloroform-isoamylalcohol (25:24:1). The nucleic acid extract was then treated with RNase-free DNase 1 to remove any contaminating genomic DNA, and extracted again with phenol-chloroform-isoamylalcohol (25:24:1). Total nucleic acid (primarily rRNA) was precipitated by the addition of $3 \mathrm{M}$-sodium acetate $(0 \cdot 1$ volumes $)$ and isopropanol $(0 \cdot 7$ volumes). The RNA pellets were washed with $70 \%$ ethanol and resuspended in sterile RNase-free water before final purification with an equal volume of $13 \%$ polyethylene glycol (8000); $1.6 \mathrm{M}-\mathrm{NaCl}$. Purified RNA was then resuspended in sterile RNase-free water and stored at $-80^{\circ} \mathrm{C}$. RNA integrity was assessed by agarose gel electrophoresis.

\section{Quantitative oligonucleotide hybridisation}

Oligonucleotide probes, targeted to specific bacterial populations of intestinal ecosystems ${ }^{(19)}$, were $5^{\prime}$-end labelled with ${ }^{32} \mathrm{P}$ using polynucleotide kinase and $\left[\gamma_{-}{ }^{32} \mathrm{P}\right] \mathrm{ATP}$. A tenfold excess of the amount of probe necessary to bind to rRNA applied to the membrane was added to $3 \mu$ l of $10 \times$ kinase buffer, $3 \mu \mathrm{l}$ of $10 \mathrm{~mm}$-spermidine, $1 \mu \mathrm{l}$ of polynucleotide kinase (New England Biolabs (UK) Limited, Hitchin, Herts, 
$\mathrm{UK})$, an equimolar amount of end-labelling grade $\left[\gamma^{-}{ }^{32} \mathrm{P}\right]$ ATP (Perkin Elmer LAS, Beaconsfield, Bucks, UK), and RNase-free water in a total volume of $30 \mu \mathrm{l}$. The reaction was then incubated at $37^{\circ} \mathrm{C}$ for $30 \mathrm{~min}$. Unincorporated ${ }^{32} \mathrm{P}$ was removed from labelled probes using NICK columns (GE Healthcare UK Limited, Little Chalfont, Bucks, UK). Extracted RNA at $100 \mu \mathrm{g} / \mathrm{ml}$ was denatured by the addition of $2 \%$ (v/v) glutaraldehyde and diluted to a final concentration of $4 \mu \mathrm{g} / \mathrm{ml}$ with RNase-free water containing $1 \mu \mathrm{g}$ Poly(A)/ml and $0.02 \mu \mathrm{l}$ of $2 \%(\mathrm{w} / \mathrm{v})$ bromophenol blue/ml. A $100 \mu$ l volume sample $(400 \mathrm{ng}$ ) was then applied in triplicate to a positively charged nylon membrane (Hybond N+; GE Healthcare UK Limited) using a slot-blot device under vacuum (Scotlab, Coatbridge, Scotland, UK). Dilution series of known SSU rRNA amounts from appropriate positive controls were included as hybridisation standards on each membrane. The membranes were air dried and rRNA was fixed to the membrane by UV cross-linking (UV Stratalinker 2400; Agilent Technologies, Amsterdam, The Netherlands).

The membranes were prehybridised for $2 \mathrm{~h}$ at $40^{\circ} \mathrm{C}$ in a

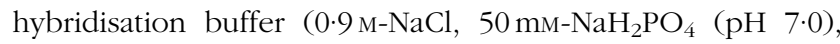
$5 \mathrm{~mm}$-EDTA, $10 \times$ Denhardt's solution, $0.5 \%(\mathrm{w} / \mathrm{v})$ SDS and $0.1 \mathrm{mg}$ Poly $(\mathrm{A}) / \mathrm{ml})$ before the addition of $400 \mu \mathrm{l}$ labelled probe in a volume of $10 \mathrm{ml}$ hybridisation buffer. Hybridisation was performed for $16-18 \mathrm{~h}$ at $40^{\circ} \mathrm{C}$. After hybridisation, the membranes were washed in $1 \times$ saline-sodium citrate buffer; $1 \%(\mathrm{w} / \mathrm{v})$ SDS for $15 \mathrm{~min}$ at $40^{\circ} \mathrm{C}$, followed by washing twice at the appropriate wash temperature for $30 \mathrm{~min}$ as described previously ${ }^{(19)}$.

Total SSU rRNA abundance was inferred by the use of a universal hybridisation probe (Univ1390) complementary to all characterised SSU rRNA ${ }^{(21)}$. Following exposure to X-ray film (Kodak MS; Eastman-Kodak, Henel Hempstead, Herts, UK), hybridisation signals were quantified by scanning densitometry using Phoretix 1D Quantifier v.5.10 (Nonlinear Dynamics, Newcastle-upon-Tyne, UK). For the quantification of SSU rRNA, standard curves were constructed by linear regression from the known SSU rRNA amounts applied to each membrane. The relative population abundance of specific bacterial groups was then calculated as a fraction of the total SSU rRNA abundance as determined by the hybridisation of the universal probe.

\section{Measurement of microbial metabolites}

Thawed intestinal contents were centrifuged at $13000 \mathrm{~g}$ (Eppendorf 5415C; Eppendorf UK Limited, Cambridge, UK) and the supernatants were removed for the determination of monocarboxylic acid concentration. The method of Richardson et al. ${ }^{(22)}$ was used to measure the concentrations of naturally occurring monocarboxylic acids (butyric, propionic and acetic) and other analogues (lactic, valeric and isobutyric acids). Briefly, to $1 \mathrm{ml}$ of gut content liquor, $50 \mu \mathrm{l}$ of an internal standard ( $0 \cdot 1 \mathrm{~m}$-2-ethyl butyric acid) were added. Monocarboxylic acids were then extracted by the addition of concentrated $\mathrm{HCl}$ and diethyl ether. The diethyl ether layer extract was derivatised, and the monocarboxylic acids and derivatives were separated by capillary GC and quantified in relation to the internal standard.

\section{Statistical analysis}

Data in Figs. 1-3 are presented as medians (interquartiles). The points represent individual animals. The significance of differences was determined by using the Mann-Whitney $U$ test for non-normally distributed data (GraphPad Prism 5; GraphPad Software, Inc. La Jolla, CA, USA). The results were considered significant if $P<0.05$. $P$ values were confirmed by one-way repeated-measures ANOVA with Bonferroni's multiple comparison test.

The data in Table 1 are presented as means and standard errors. The significance of differences was determined using Student's $t$ test (GraphPad Prism 5; GraphPad Software, Inc.). The results were considered significant if $P<0.05$. $P$ values were confirmed by one-way repeated-measures ANOVA with Bonferroni's multiple comparison test.

\section{Results}

\section{Alteration in microbiota in response to dietary change and intestinal dysfunction}

To characterise the major microbial populations present in the equine colon, we used oligonucleotide-RNA hybridisation to determine the relative population sizes of the specific (a)

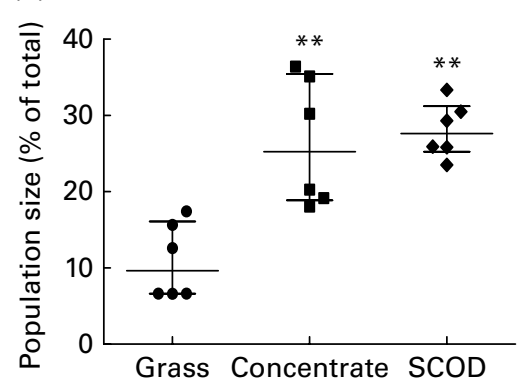

(b)

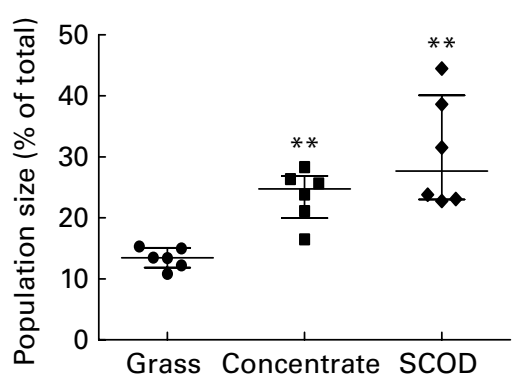

(c)

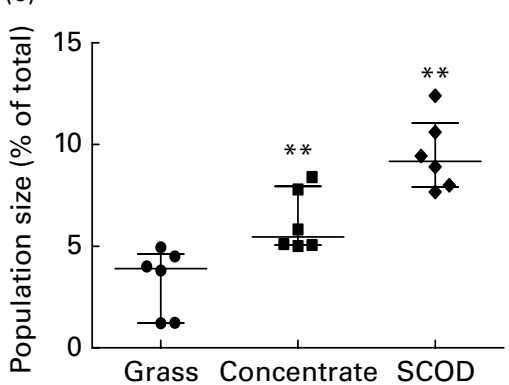

Fig. 1. Increased population abundance of the (a) Lachnospiraceae (cluster XIVa of the Clostridiaceae), (b) Bacteroidetes assemblage (Cytophaga-FlexibacterBacteroides) and (c) Bacillus-Lactobacillus-Streptococcus group in concentrate-fed and simple colonic obstruction and distension (SCOD) horses compared with grass-fed horses, as determined by quantitative oligonucleotide-RNA hybridisation. Data are presented as medians and interquartiles, $n$. Points represent individual animals. Significance of differences was determined using the Mann-Whitney $U$ test for non-normally distributed data (GraphPad Prism 5; GraphPad Software, Inc.). Results were considered significant if $P<0.05$. $P$ values were confirmed by one-way repeated-measures ANOVA with Bonferroni's multiple comparison test. ${ }^{* \star}$ Values were significantly different from that of the grass-fed group $(P<0.01)$. 
(a)

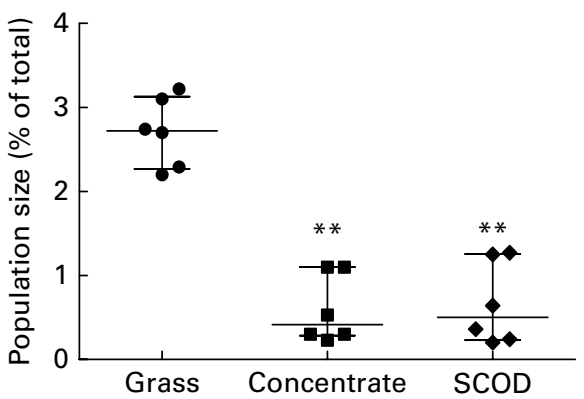

(b)

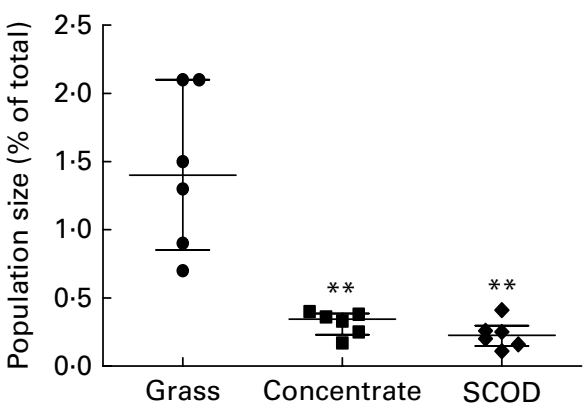

Fig. 2. Decreased population abundance of (a) Fibrobacter spp. and (b) Ruminococcaceae (cluster IV of the Clostridiaceae) in concentrate-fed and simple colonic obstruction and distension (SCOD) horses compared with grass-fed horses, as determined by quantitative oligonucleotide-RNA hybridisation. Data are presented as in Fig. 1. ${ }^{\star *}$ Values were significantly different from that of the grass-fed group $(P<0.01)$.

microbial communities. Bacterial SSU rRNA, extracted from colonic contents of three different groups of horses, was used in conjunction with seven different group-specific oligonucleotide probes to quantify predominant bacterial populations.

The abundance of Lachnospiraceae (cluster XIVa of the Clostridiaceae) and the Bacteroidetes (CFB), targeted by probes EREC482 ${ }^{(23)}$ and $\mathrm{CFB} 935^{(19)}$, respectively, were significantly greater in concentrate-fed horses and in concentrate-fed horses suffering from SCOD in comparison with horses maintained on grass diet only.

The median population size of the Lachnospiraceae in horses on grass ( $n$ 6) was $9.6 \%$ of the total microbiota. However, the population size of this group was higher in all concentrate-fed horses and those with SCOD. The median population sizes were greater, with $25.2 \%$ in the former ( $n 6 ; P<0.01$ ) and $27.6 \%$ in the latter group of horses $(n 6$; $P<0 \cdot 01$ ) (Fig. 1(a)).

The median population size of the Bacteroidetes assemblage in grass-fed horses was $13.5 \%(n 6)$. This population was $24.7 \%$ in concentrate-fed horses ( $n 6 ; P<0.01)$, with all six horses having a significantly higher population. The median population size of the Bacteroidetes in horses with SCOD was $27.7 \%(n 6 ; P<0.01)$, with all six horses possessing a significantly higher proportion of Bacteroidetes microbes (Fig. 1(b)).
Similar to the Lachnospiraceae group and the Bacteroidetes assemblage, there was a higher relative population size of the BLS group in both concentrate-fed and SCOD horses. The median population size, as determined by the BLS1295 probe $^{(19)}$, was $5.5 \%(n 6 ; P<0.01)$ in concentrate-fed horses and $9.2 \%$ in horses with SCOD $(n 6 ; P<0 \cdot 01)$. This compares with the median population size in grass-fed horses of $3.9 \%$ ( $n$ 6). All concentrate-fed and SCOD horses contained significantly higher numbers of the BLS group than horses fed on grass only (Fig. 1(c)).

Contrasting effects on other microbial populations were observed in the study groups. The median population size of the Fibrobacter group in grass-fed horses was $2.7 \%$, as measured by the FIB225 probe ${ }^{(24)}$. However, in concentratefed horses and those with SCOD, Fibrobacter comprised $0 \cdot 4$ and $0.5 \%$, respectively ( $n 6 ; P<0.01$ for both groups); all concentrate-fed and SCOD horses contained significantly less Fibrobacter compared with those given grass (Fig. 2(a)).

Using the IV815 probe ${ }^{(19)}$, we determined the median population size of the Ruminococcaceae (clostridial cluster IV) to be significantly lower in concentrate-fed horses without $(0.3 \% ; n 6 ; P<0 \cdot 01)$ and with SCOD $(0.2 \% ; n 6 ; P<0 \cdot 01)$ compared with grass-fed horses (1.4\%). Again, all concentrate-fed horses and all horses with SCOD had significantly less Ruminococcaceae than those on grass (Fig. 2(b)). (a)

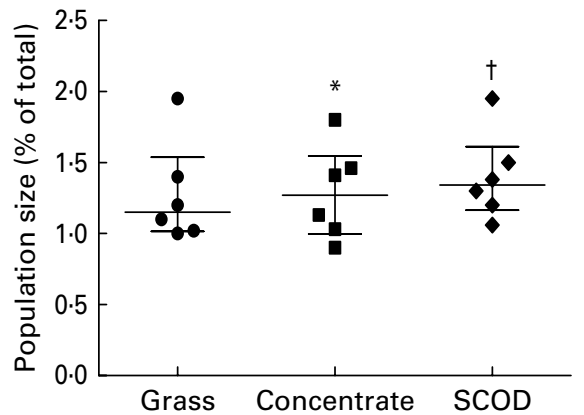

(b)

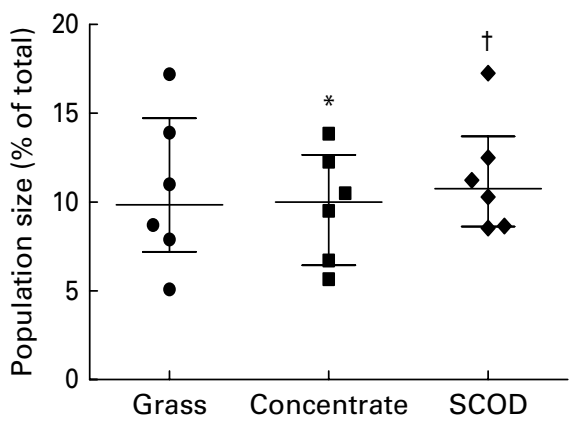

Fig. 3. Population abundance of (a) Veillonellaceae (cluster IX of the Clostridiaceae) and (b) the Spirochaetaceae, as determined by quantitative oligonucleotideRNA hybridisation, showing no significant differences between grass-fed, concentrate-fed and simple colonic obstruction and distension (SCOD) horses. Data are presented as in Fig. 1. (a) Values were not significantly different for concentrate-fed and SCOD horses from that of the grass-fed group, respectively: ${ }^{\star} P=0.82$; $\dagger P=0.38$. (b) Values were not significantly different for concentrate-fed and SCOD horses from that of the grass-fed group, respectively: ${ }^{\star} P=0 \cdot 82$; $\dagger P=0 \cdot 70$. 
Table 1. Concentration of monocarboxylic acids in equine colonic contents (Mean values with their standard errors)

\begin{tabular}{|c|c|c|c|c|c|c|}
\hline \multirow{3}{*}{$\begin{array}{l}\text { Monocarboxylic } \\
\text { acid }\end{array}$} & \multicolumn{6}{|c|}{ Concentration (mM) } \\
\hline & \multicolumn{2}{|c|}{$\begin{array}{l}\text { Grass-fed } \\
\quad(n 6)\end{array}$} & \multicolumn{2}{|c|}{$\begin{array}{c}\text { Concentrate-fed } \\
(n 6)\end{array}$} & \multicolumn{2}{|c|}{$\operatorname{SCOD}(n 6)$} \\
\hline & Mean & SEM & Mean & SEM & Mean & SEN \\
\hline Acetic acid & 55.5 & $2 \cdot 1$ & $44 \cdot 7$ & 3.9 & $50 \cdot 1$ & 4.2 \\
\hline Propionic acid & $11 \cdot 1$ & 0.9 & $12 \cdot 4$ & 1.5 & $14 \cdot 0$ & 0.8 \\
\hline Butyric acid & $2 \cdot 9$ & 0.3 & 3.7 & 0.5 & 3.7 & 0.5 \\
\hline Lactic acid & 1.0 & 0.3 & $2 \cdot 5^{\star}$ & 0.2 & $6 \cdot 0^{* *}$ & 1.0 \\
\hline Isobutyric acid & 1.3 & 0.1 & 1.3 & 0.1 & 1.5 & 0.2 \\
\hline Valeric acid & 0.4 & 0.1 & 0.6 & 0.1 & 0.6 & 0.1 \\
\hline
\end{tabular}

SCOD, simple colonic obstruction and distension.

Mean values were significantly different from that of the grass-fed group and were determined using Student's $t$ test and one-way repeated-measures ANOVA ${ }^{*} P<0.05 ;{ }^{*} P<0.01$.

The median population level of Veillonellaceae (probably lactate-utilising microbes) in grass-fed horses was $1.2 \%$ of total, as determined by the IX854 probe ${ }^{(19)}$. There was no difference in the relative population size of this microbial group in horses that were either maintained on a concentrate diet or had developed SCOD (median population sizes $1.3 \%$ for both groups) (Fig. 3(a))

The Spirochaetaceae is a major component of the equine colonic microbiota, comprising up to $15 \%$ of total ${ }^{(19)}$. Use of the Spiro1400 probe in the present study showed that the median population size of this group was similar in all three sets of animals (grass 9.9\%; concentrate 10.0\%; SCOD 10.8\%) (Fig. 3(b)).

\section{Changes in microbial metabolites}

The mean concentration of lactic acid in the colonic contents of horses fed only on grass was $1.0 \mathrm{~mm}(n 6)$, with one horse having no detectable lactic acid. However, the mean steadystate concentration of lactic acid in colonic contents of horses consuming concentrate or having developed SCOD were $2.5 \mathrm{~mm}(n 6 ; P<0.01)$ and $6.0 \mathrm{~mm}(n 6 ; P<0.01)$, respectively (Table 1 ). The concentrations of other monocarboxylic acids (acetic, propionic, butyric, valeric and isobutyric), although variable among individuals, were not significantly different in the intestinal contents of the three groups of horses (Table 1).

\section{Discussion}

In the present study, we show that the population sizes of the Lachnospiraceae, the Bacteroidetes (CFB) assemblage and the BLS group are significantly greater in horses fed concentrate and those with the clinical diagnosis of SCOD.

The Lachnospiraceae group is a large and diverse cluster of both fibrolytic and saccharolytic microbes including Clostridium spp., Butyrivibrio spp., Ruminococcus spp. and Eubacterium spp. The Bacteroidetes assemblage in equine colon is comprised mainly of Bacteroides and Prevotella spp., which are predominantly saccharolytic and will readily ferment
$\mathrm{hCHO}^{(25)}$. Members of both groups possess the ability to express many different genes involved in fibrolytic/saccharolytic digestion and as such can readily adapt to changes in substrate availability ${ }^{(26,27)}$. The enhancement in relative population sizes of these groups is probably a reflection of the increased competitiveness of adaptable members, compared with those that are obligate fibrolytics, in response to the increased amount of hCHO available as substrate.

Members of the BLS, Gram-positive, lactic acid-producing species, favour hCHO as a substrate for fermentation. They do not ferment structural carbohydrates directly but utilise oligosaccharides, released by fibrolytic organisms. They will react rapidly to the availability of more readily fermentable substrates ${ }^{(28,29)}$ proliferating in a starch-rich environment producing excess amounts of lactic acid and $\mathrm{CO}_{2}{ }^{(17,30)}$. Members of this group, notably Streptococcus bovis, have long been implicated in the aetiology of lactic acidosis both in horses and in ruminants ${ }^{(28-32)}$.

In contrast, Fibrobacter spp. and members of the Ruminococcaceae (clostridial cluster IV) are obligate fibrolytic, predominantly acid-intolerant bacteria whose growth is greatly suppressed at acidic $\mathrm{pH}^{(33-36)}$. The median proportions of these bacterial populations were significantly lower in horses fed concentrate or undergoing surgery for SCOD, suggesting a more acidic colonic pH. Fibrobacter and Ruminococcaceae ferment dietary fibre to SCFA ${ }^{(37)}$. The lower population size of these groups would be expected to result in a reduction in fibre digestion and hence concentrations of intraluminal SCFA. However, our data indicate that the overall concentrations of SCFA remained the same in the intestine of the three study groups of animals. We speculate that this may be due to inhibition of SCFA transport in the intestine of concentrate-fed horses by lactate, a competitive inhibitor of the SCFA transporter, monocarboxylate transporter $1^{(38-40)}$.

There were significantly higher concentrations of lactic acid in the colonic contents of concentrate-fed horses and those with SCOD compared with grass-fed horses (2.5- and 6-fold higher concentrations, respectively), correlating with the observed greater population abundance of the BLS group. It has been demonstrated that there is a significant increase in lactic acid concentration in the colon of horses fed highgrain diets ${ }^{(15)}$. This is accompanied by a marked decrease in caecal/colonic $\mathrm{pH}$ (from $>7 \cdot 5$ to $<6 \cdot 2)^{(15,16)}$. Lactic acid (as opposed to acetic, butyric or propionic acids) is much more likely to cause drastic alterations in colonic $\mathrm{pH}$ due to its relatively low $\mathrm{p} K_{\mathrm{a}}$ of $3 \cdot 86$, thus making it a stronger acid than the other SCFA (the $\mathrm{p} K_{\mathrm{a}}$ of acetic, butyric and propionic acids are $4 \cdot 76,4.82$ and 4.87 , respectively).

Despite the higher lactic acid concentration, the population size of the Veillonellaceae (lactate utilisers; cluster IX of the Clostridiaceae) was similar (approximately $1 \%$ of total) in each study group of horses. In contrast, representatives of this group can comprise up to $10 \%$ of the total microbial population in the human colon ${ }^{(41)}$. In addition, one important group of Lachnospiraceae found in human colon (related to Eubacterium hallii and Anaerostipes spp.) has the ability to convert lactate to butyrate ${ }^{(42)}$. Consequently, in humans, most of the lactic acid produced by the fermentation of 
resistant starch reaching the colon is converted into butyrate and propionate ${ }^{(43,44)}$. Similarly, in the rumen members of the Veillonellaceae, such as Selenomonas spp., often produce lactate, but many strains can convert lactate into propionate ${ }^{(45)}$. However, in horses maintained on grass, the median population size of Veillonellaceae was just over $1 \%$ of the total; there was also very little lactic acid present in their colonic contents. The smaller population size of this group in horses may be sufficient when horses are maintained on their natural diet (grass), but an inability to adapt to changes in the colonic environment may contribute to the observed increase in lactic acid.

In order to provide energy for the demands of work and athletic performance, many horses are fed diets containing $\mathrm{hCHO}$, generally in the form of grain (concentrate diet). It is proposed that when they are introduced to diets containing high levels of hCHO ( $>0.4 \%$ of body weight), a substantial proportion of starch reaches the large intestine ${ }^{(12-14)}$ causing drastic alteration in microbiota, microbial fermentation products and perturbing caecal and colonic $\mathrm{pH}^{(1,15-17)}$ disposing the horse to intestinal dysfunction. Horses have low levels of pancreatic $\alpha$-amylase, and hence an inability to hydrolyse large amounts of starch, compared with omnivorous species ${ }^{(46,47)}$. It has been shown, in other species, that activity of $\alpha$-amylase increases in response to dietary $\mathrm{hCHO}^{(48,49)}$. There is evidence that horses are also able to enhance the activity of this enzyme in response to increased dietary $\mathrm{hCHO}$, but this is a lengthy process requiring up to 2-3 weeks $^{(14)}$. Furthermore, the timescale of increased risk of SCOD $^{(6)}$ indicates maximum danger during the $7 \mathrm{~d}$ following dietary change (hCHO supplementation), with risk declining to baseline levels by $14 \mathrm{~d}$. This is consistent with the time required for up-regulation of intestinal $\alpha$-amylase.

Diet has been shown to influence intestinal microbiota resulting in microbial products either beneficial or harmful to the host ${ }^{(50,51)}$. In the present study, we have shown that equine intestinal microbiota are different in horses fed diets varying in $\mathrm{hCHO}$, and that these differences are more exaggerated in a model of dietary-induced intestinal disease. The data demonstrate that differences in diet correlate well with alterations in intestinal microbial ecosystems and production of microbial fermentation products (such as lactic acid), thus creating environments predisposing the host to intestinal diseases.

To further explore associations between dietary change, microbiota and risk of intestinal disease, a case-control study design, where horses of similar age, background and exercise regimen can be managed before dietary intervention, will provide a more direct comparison. A better understanding of molecular mechanisms involved in diet, microbiota and host interactions will allow a more scientifically based approach to designing food formulation, supplementation and management with the ultimate aim of enhancing the health of the species.

\section{Acknowledgements}

The financial support of the Horserace Betting Levy Board is gratefully acknowledged. The authors' contributions are as follows: S. P. S.-B. and K. D. designed the study. K. D. performed the study. S. P. S.-B., K. D. and J. D. analysed the data. C. J. P. provided equine colonic samples and dietary/ clinical advice. S. H. D. and H. J. F. provided the analytical data on metabolite measurements. S. P. S.-B. and K. D. wrote the manuscript. The authors declare that there is no conflict of interest.

\section{References}

1. Clarke LL, Roberts MC \& Argenzio RA (1990) Feeding and digestive problems in horses. Physiologic responses to a concentrated meal. Vet Clin North Am Equine Pract 6, $433-450$.

2. Hintz HF \& Cymbaluk NF (1994) Nutrition of the horse. Ann Rev Nutr 14, 243-267.

3. Tinker MK, White NA, Lessard P, et al. (1997) A prospective study of equine colic risk factors. Equine Vet J 29, 454-458.

4. Hudson JM, Cohen ND, Gibbs PG, et al. (2001) Feeding practices associated with colic in horses. J Am Vet Med Assoc 219, 1419-1425.

5. Gonçalves S, Julliand V \& Leblond A (2002) Risk factors associated with colic in horses. Vet Res 33, 641-652.

6. Hillyer MH, Taylor FG, Proudman CJ, et al. (2002) Case control study to identify risk factors for simple colonic obstruction and distension colic in horses. Equine Vet J34, 455-463.

7. Archer DC \& Proudman CJ (2006) Epidemiological clues to preventing colic. Vet J 172, 29-39.

8. Argenzio RA, Southworth M \& Stevens CE (1974) Sites of organic acid production and absorption in the equine gastrointestinal tract. Am J Physiol 226, 1043-1050.

9. Argenzio RA (1975) Functions of the equine large intestine and their interrelationship in disease. Cornell Vet $\mathbf{6 5}$, 303-327.

10. Bergman EN (1990) Energy contributions of volatile fatty acids from the gastrointestinal tract in various species. Physiol Rev 70, 567-590.

11. Cohen ND, Gibbs PG \& Woods AM (1999) Dietary and other management factors associated with colic in horses. $\mathrm{J} \mathrm{Am} \mathrm{Vet}$ Med Assoc 215, 53-60.

12. Potter GD, Arnold FF, Householder DD, et al. (1992) Digestion of starch in the small and large intestine of the equine. Pferdeheilkunde 1, 107-111.

13. Lopes MA, White NA, Crisman MV, et al. (2004) Effects of feeding large amounts of grain on colonic contents and faeces in horses. Am J Vet Res 65, 687-694.

14. Dyer J, Al-Rammahi M, Waterfall L, et al. (2009) Adaptive response of equine intestinal $\mathrm{Na}^{+}$/glucose co-transporter (SGLT1) to an increase in dietary soluble carbohydrate. Pflugers Arch 458, 419-430.

15. Medina B, Girard ID, Jacotot E, et al. (2002) Effect of a preparation of Saccharomyces cerevisiae on microbial profiles and fermentation patterns in the large intestine of horses fed a high fiber or a high starch diet. J Anim Sci 80, 2600-2609.

16. Julliand V, De Frombelle A, Drogoul C, et al. (2001) Feeding and microbial disorders in horses: 3-effects of three hay:grain ratios on microbial profiles and activities. $J$ Equine Vet Sci 21, 543-546.

17. Goodson J, Tyznik WJ, Cline JH, et al. (1988) Effects of an abrupt diet change from hay to concentrate on microbial numbers and physical environment in the cecum of the pony. Appl Environ Microbiol 54, 1946-1950.

18. Daly K, Stewart CS, Flint HJ, et al. (2001) Bacterial diversity within the equine large intestine as revealed by molecular 
analysis of cloned 16S rRNA genes. FEMS Microbiol Ecol 38, 141-151.

19. Daly K \& Shirazi-Beechey SP (2003) Design and evaluation of group-specific oligonucleotide probes for quantitative analysis of intestinal ecosystems: their application to assessment of equine colonic microflora. FEMS Microbiol Ecol 44 , $243-252$.

20. Lin C \& Stahl DA (1995) Taxon-specific probes for the cellulolytic genus Fibrobacter reveal abundant and novel equine-associated populations. Appl Environ Microbiol 61, $1348-1351$.

21. Zheng D, Alm EW, Stahl DA, et al. (1996) Characterization of universal small-subunit rRNA hybridization probes for quantitative molecular microbial ecology studies. Appl Environ Microbiol 62, 4504-4513.

22. Richardson AJ, Calder AG, Stewart CS, et al. (1989) Simultaneous determination of volatile and non-volatile acidic fermentation products of anaerobes by capillary gas chromatography. Lett Appl Microbiol 9, 5-8.

23. Franks AH, Harmsen HJ, Raangs GC, et al. (1998) Variations of bacterial populations in human faeces measured by fluorescent in situ hybridization with group-specific $16 \mathrm{~S}$ rRNA-targeted oligonucleotide probes. Appl Environ Microbiol 64, 3336-3345.

24. Stahl DA, Flesher B, Mansfield HR, et al. (1988) Use of phylogenetically based hybridization probes for studies of ruminal microbial ecology. Appl Environ Microbiol 54, 1079-1084.

25. Salyers AA (1990) Polysaccharide utilization by human colonic bacteria. Adv Exp Med Biol 270, 151-158.

26. Schwarz WH, Zverlov VV \& Bahl H (2004) Extracellular glycosyl hydrolases from clostridia. Adv Appl Microbiol 56, 215-261.

27. Backhed F, Ley RE, Sonnenburg JL, et al. (2005) Hostbacterial mutualism in the human intestine. Science $\mathbf{3 0 7}$, $1915-1920$

28. Nocek JE (1997) Bovine acidosis: implications on laminitis. J Dairy Sci 80, 1005-1028.

29. Owens FN, Secrist DS, Hill WJ, et al. (1998) Acidosis in cattle: a review. J Anim Sci 76, 275-286.

30. Goad DW, Goad CL \& Nagaraja TG (1998) Ruminal microbial and fermentative changes associated with experimentally induced subacute acidosis in steers. J Anim Sci 76, 234-241.

31. Rowe JB, Lees MJ \& Pethick DW (1994) Prevention of acidosis and laminitis associated with grain feeding in horses. J Nutr 124, 2742S-2744S.

32. Russell JB \& Rychlik JL (2001) Factors that alter ruminal microbial ecology. Science 292, 1119-1122.

33. Russell JB \& Dombrowski DB (1980) Effect of pH on the efficiency of growth by pure cultures of rumen bacteria in continuous culture. Appl Environ Microbiol 39, 604-610.

34. Miyazaki K, Hino T \& Itabashi H (1992) Effects of extracellular $\mathrm{pH}$ on the intracellular $\mathrm{pH}$ and membrane potential of cellulolytic ruminal bacteria, Ruminococcus albus, Ruminococcus flavefaciens, and Fibrobacter succinogenes. J Gen Appl Microbiol 38, 567-573.
35. Asanuma N \& Hino T (1997) Tolerance to low pH and lactate production in rumen bacteria. Anim Sci Technol 68, $367-376$

36. Miwa T, Esaki H, Umemori J, et al. (1997) Activity of H(+)ATPase in ruminal bacteria with special reference to acid tolerance. Appl Environ Microbiol 63, 2155-2158.

37. Dehority BA (1993) Microbial ecology of cell wall fermentation. In Forage Cell Wall Structure and Digestibility, pp. 425-453 [HG Jung, DR Buxton, RD Hatfield and J Ralph, editors]. Madison, WI: ASA-CSSA-SSSA.

38. Ritzhaupt A, Ellis A, Hosie KB, et al. (1998) The characterization of butyrate transport across pig and human colonic luminal membrane. J Physiol 507, 819-830.

39. Cuff MA, Lambert DW \& Shirazi-Beechey SP (2002) Substrate-induced regulation of the human colonic monocarboxylate transporter, MCT1. J Physiol 539, 361-371.

40. Shirazi-Beechey SP (2008) Molecular insights into dietary induced colic in the horse. Equine Vet J 40, 414-421.

41. Duncan SH, Belenguer A, Holtrop G, et al. (2007) Reduced dietary intake of carbohydrates by obese subjects results in decreased concentrations of butyrate and butyrateproducing bacteria in faeces. Appl Environ Microbiol 73, 1073-1078.

42. Duncan SH, Louis P \& Flint HJ (2004) Lactate utilizing bacteria, isolated from human feces, that produce butyrate as a major fermentation product. Appl Environ Microbiol 70, $5810-5817$.

43. Stewart CS, Flint HJ \& Bryant MP (1997) The rumen bacteria. In The Rumen Microbial Ecosystem, 2nd ed., pp. 10-72 [PN Hobson and CS Stewart, editors]. London: Blackie Academic and Professional.

44. Bourriaud C, Robins RJ, Martin L, et al. (2005) Lactate is mainly fermented to butyrate by human intestinal microflora but inter-individual variation is evident. J Appl Bacteriol 99, 201-212.

45. Belenguer A, Duncan SH, Holtrop G, et al. (2007) Impact of $\mathrm{pH}$ on lactate formation and utilisation by rumen fecal microbial communities. Appl Environ Microbiol 73, 6526-6533.

46. Roberts MC (1974) Amylase activity in the small intestine of the horse. Res Vet Sci 17, 400-401.

47. Kienzle E, Radicke S, Landes E, et al. (1994) Activity of amylase in the gastrointestinal tract of the horse. J Anim Physiol Anim Nutr 72, 234-241.

48. Brannon PM (1990) Adaptation of the exocrine pancreas to diet. Annu Rev Nutr 10, 85-105.

49. Swanson KC, Matthews JC, Matthews AD, et al. (2000) Dietary carbohydrate source and energy intake influence the expression of pancreatic alpha-amylase in lambs. $J$ Nutr 130, 2157-2165.

50. Beards E, Tuohy K \& Gibson G (2010) A human volunteer study to assess the impact of confectionery sweeteners on the gut microbiota composition. Br J Nutr 104, 701-708.

51. Benus RF, van der Werf TS, Welling GW, et al. (2010) Association between Faecalibacterium prausnitzii and dietary fibre in colonic fermentation in healthy human subjects. Br J Nutr 104, 693-700. 